advance of equal importance to the 19th century acts on children's education and employment. Many aspects of the new Act reflect the fresh approach: for example, section 29 provides that if a child has been fostered for at least five years the foster parents can apply to the court for a short period of "freeze," during which the child stays with them. While the natural parents apply to have the child back the care workers have time to assess the problem and to prepare the child. Nevertheless, the 1948 Act may still need to be used for children already in care, for it looks at the parent (not the child) and asks, Is he fit to care for the child ? Parents who may be considered unfit under this Act include those suffering from mental disorder, those whose habits and mode of life are unsatisfactory, and those who have not discharged their parental obligations. Invocation of this Act could prevent a parent from turning up at a children's home and removing his child without warning.

A recurrent problem experienced by many doctors working with children at risk is that only social workers have a statutory authority to apply for a care or place-of-safety order. Occasionally an experienced paediatrician is in the disheartening position of watching his patient leave the ward to return to a family which he knows is dangerous because a relatively inexperienced social worker does not think an order is necessary. Doctors closely concerned with this work would be happier if they too were able to apply for a place-of-safety order, so giving time for further thought.

Perhaps, too, we should look again at the implications of "children's rights" for parents. Most of us have hopes, ideals, and plans for our children, and society should be able to interfere with these only in exceptional circumstances. How far should society be free to condemn parents as neglectful? In relatively minor matters, such as immunisation, recourse to the courts is no solution. One possibility we should perhaps consider the French system ${ }^{2}$ of paying family allowances only to those families which have completed all the recommended health procedures. Parents will have to learn that the State is prepared to protect the right of each child to maximum health and normal development-but the message is likely to get across more quickly with a carrot than with a stick.

\footnotetext{
${ }^{1}$ Conference on dimensions of parenthood, The Family and Society, (paper by Uri Bronfenberger). London, HMSO

2 Wynn, M, and Wynn, A, The Right of Every Child to Health Care: $A$ study of the protection of the young child in France. London, Foundation for Education and Research in Childbearing, 1974.
}

\section{Behaviourism: a framework for common sense therapy}

Walking is healthy, yet few of us take enough exercise. If a doctor advises an obese patient to take more exercise, the chances are that he won't. Yet persuade his wife to give him a puppy for his birthday and he will probably walk the soles off his shoes for the sake of his dog. Similarly, many housewives lead lives of bitter loneliness only yards away from other women who are longing for their company. It is no good advising them to knock on their neighbours' doors; they just can't. Yet provide them with a communal room with washing machines and they will meet and gradually develop friendships. In other words, common sense is not enough. The man knows he should walk, the woman knows she should mix with others, but they cannot or will not do it unless they are provided with a framework.
Behaviour therapy is a framework for applying common sense to behavioural problems, particularly the application of common sense rewards and punishments. The earliest and most successful behavioural treatments were of phobias such as fear of animals or of going to the shops. At first the method used was desensitisation, a very gradual approach to the feared object in fantasy or in fact with simultaneous relaxation to provide reciprocal inhibition of the anxiety. Recent studies have shown that equal or even greater success can be achieved more quickly by "flooding" (implosion), in which the patient remains in contact with the feared object for a long time until his fear is exhausted and he can then learn to deal with it without phobia. Now all this is common sense: anyone who has been swimming knows that there are two ways to enter icy water-down the steps gradually or diving in from the deep end. But in the case of phobias the knowledge is not enough, any more than it is enough for the man to know he must take exercise. So it is not usually effective to sit in the consulting room and tell the agorophobic patient that she might go a little further every day until she gains her confidence, or that she must go and spend hours in a supermarket until her anxiety is replaced by boredom. She will not do it. But she will do it if she is provided with the framework of behaviour therapy. Clearly the behaviour therapist does far more than just provide a framework for the application of common sense, but in a fundamental way he is performing the function which the puppy does for the obese man and the common laundry does for the lonely woman.

The practice of behaviour therapy is supported by an enormous amount of subtle theorising and ingenious research. ${ }^{1}$ The animal studies started in the early years of this century in the laboratory of Pavlov, ${ }^{2}$ who showed that when restrained dogs were asked to make a difficult discrimination between a circle and an ellipse some of them showed strongly emotional reactions such as howling, biting, and struggling to be free of the harness. The first human study was reported by Watson and Rayner in $1920 .^{3}$ They chose a 9-month-old boy called Albert, who was not afraid of fur or white rats but was distressed by a loud and unpleasant noise. After seven applications of noise while Albert reached out for the white rat, the child became afraid of it and this fear generalised to similar objects such as a fur coat. Many other experiments followed, showing that conditioned emotional reactions (experimental neuroses) could be induced by various techniques such as conflict and noxious stimulation in many species. In most cases the experimental neuroses could be cured by behavioural methods such as desensitisation. The work has developed ${ }^{4}$ beyond phobias into sexual disorders, tics, obsessivecompulsive neurosis, bad habits such as smoking and drinking -and even into depressive illness, which is regarded as a form of "learned helplessness" and may be treated by positive reinforcement (reward). ${ }^{5}$ This extension of behaviour therapy, and particularly its further extension to the treatment of delinquents, has not gone without criticism, ${ }^{6}$ and it is noteworthy that when behaviour therapists have required treatment themselves they have not yet considered behaviour therapy to be indicated. ${ }^{\text {? }}$

It is difficult to know how relevant the theories and experimental results of behaviourism are to behaviour therapy. Possibly in some cases they have actually retarded its progress. Masserman, ${ }^{8}$ for example, having made cats phobic of one food by blasting them with air while feeding, tried to cure the phobia by keeping them in prolonged contact with the food in the absence of any noxious stimulus. The method did not work; on the other hand, gradual desensitisation with reciprocal inhibition (petting them, or giving other food) did 
work. This result may well have delayed the introduction of flooding. Nevertheless, undoubtedly behaviourism has provided a framework for the development of behaviour therapy, which has been a framework for the application of common sense. The link may be tenuous-a controversial theory of psychosexual development provided a framework for the development of individual psychotherapy-but the need for these frameworks must surely tell us something about human psychology.

${ }^{1}$ Beech, H R, in A Textbook of Human Psychology, eds H J Eysenck and G D Wilson. Lancaster, Medical and Technical Publishing, 1976.

2 Pavlov, I P, Conditioned Reflexes. London, Oxford University Press, 1927.

3 Watson, J B, and Rayner, R, fournal of Experimental Psychology, 1920, 3, 1.

${ }^{4}$ Marks, I M, American fournal of Psychiatry, 1976, 133, 253.

5 Siligman, M E P, in The Psychology of Depression: Contemporary Theory and Research, eds R J Friedman and M M Katz. New York, John Wiley, 1974.

6 Yates, A J, Theory and Practice in Behaviour Therapy. New York, John Wiley, 1975.

${ }^{7}$ Lazarus, A A, Psychological Reports, 1971, 28, 349.

${ }^{8}$ Masserman, J H, Behaviour and Neurosis. Chicago, University of Chicago Press, 1943.

\section{Hairy legs}

Methods tried to remove hair ${ }^{1}$ from the legs have included use of the arsenic compound orpiment, hot leeches, ants' eggs, and the blood of yellow frogs. One at least of these, arcana, a syrup of sugar and water laid on the hairs and stripped off when dry, is still used for the legs in some parts of the Middle East-together with another traditional method, the plucking of hairs by a rapidly moving loop of twisted thread. ${ }^{2}$

Hair may be removed ${ }^{34}$ at the surface (depilation) by shaving, chemical degradation, and abrasion; or from the roots (epilation) by wax-the counterpart of sugar syrup-and electrolysis. Shaving is simple and cheap. Any subsequent dryness can be kept to a minimum by the use of bland creams. Shaving does not make the hair regrow faster or thicker, but has to be done frequently, and the regrowing hair has a bristly truncated end. The popular depilatory creams, sprays, and lotions are generally based on thioglycollates with calcium hydroxide or some other alkali; this combination has largely supplanted the sulphides of barium, strontium, and calcium and is less smelly. It is left on for five to 15 minutes and is then washed off. The regrowing hair is less bristly than after shaving, and, though there may be slight irritation of the skin, allergy is rare. Abrasion, though somewhat hard on the skin, can remove a light growth. Both pumice stone and sandpaper mitts to slip over the hands are available.

Waxes are usually applied warm, though a few may be used cold. The wax sets, and at a crucial moment (which is a matter of nice judgment) is pulled off with its embedded hairs. Areas of up to a few centimetres across are dealt with in succession. Some hairs may break below the surface and inflammation supervene as they grow, but this is unusual with wax-though Dilaimy ${ }^{2}$ found that it was common with the sugar syrup and thread methods. Much depends on the operator's skill, and a salon treatment may be a good investment. The regrowing hair feels natural and allergic reactions are rare. The process has to be repeated after a few weeks. Electrolygists assert that wax distorts the follicle, making later electrolysis difficult.

Permanent removal of hairs by electrolysis (galvanic or with short-wave diathermy) is formidably slow and expensive, even on facial hair; it may be surprising that it is in demand for hair on the legs. The procedure is safe if carried out by a welltrained operator, but even with frequent treatment would take at least two years. ${ }^{5}$ That it should be contemplated owes much to current mores, in which exposure to the sun of a body exiguously clad is thought to have snob value. Removal of hair from the genitocrural area ("the bikini line") may be requested, and other methods are difficult there. A new method of epilation, in which the current passes down the hair as opposed to coming from a needle inserted in the follicle, has yet to be assessed as regards safety and efficacy. Self-operated electrolysis gadgets are not to be advised.

Most women will have no difficulty in choosing a method acceptable to their individual liking and need. Racial and cultural factors affect the type of hair and attitudes towards it. Views may be changing, however: already some younger women are leaving body hair alone. The reason may be current fashion, indolence, a respect for untouched nature, women' lib, or some other individual attitude. Who can say what the custom will be ten years from now ?

1 Maxwell-Hudson, C, Kaleidoscope of Beauty. London, Octagon Press, 1968.

2 Dilaimy, M, Archives of Dermatology, 1976, 112, 507.

${ }^{3}$ Lancet, 1967, 1, 488.

4 Ridley, C M, British fournal of Dermatology, 1969, 81, 146.

5 The Permanent Removal of Superfuous Hair by Electrolysis. Blackburn, The Institute of Electrolysis.

\section{Pulmonary complications of measles}

In measles the rash is a cardinal feature, but it is possible to have measles without a rash. Disease in the respiratory tract, however, is invariable, and this is true not only of wild measles, where cough or croup precede the rash, but also of the mild reactions occasionally encountered with modern attenuated measles vaccines. Moreover, secondary pulmonary infection in measles is well known and is a recognised cause of death in measles.

What is the nature of these pulmonary changes? Measles is acquired by droplet spread, and the virus gains access to the respiratory passages by direct inoculation of the mucous membranes. Controversy still surrounds the possibility that the conjunctivae are a portal of entry, though there is experimental evidence supporting this possibility. ${ }^{1}$ At all events the virus reaches the mucosa of the respiratory tract either by droplet inoculation or by passage down the nasolachrymal sac to reach the nose.

In the respiratory epithelium the characteristic response is the formation of multinucleate giant cells. These giant cells have been described in many tissues and secretions, such as the pharynx, nasal mucosa, skin, appendix, sputum, and urine..$^{2-4}$ Indeed, the presence of giant cells in scrapings of nasal mucosa or in the urine can give laboratory support to the diagnosis of measles before the onset of the rash in much the same way as Koplik spots support the early clinical diagnosis.

Like Koplik spots giant cells are transient. They are part of the pathological evolution of the illness; they come and they go. In very few cases they persist, and in these patients the fine crepitations and high fever characteristic of early measles continue, with the development of viral pneumonitis. The onset of giant cell pneumonia at this stage of measles is probably rare. Another form of giant cell pneumonia is a 